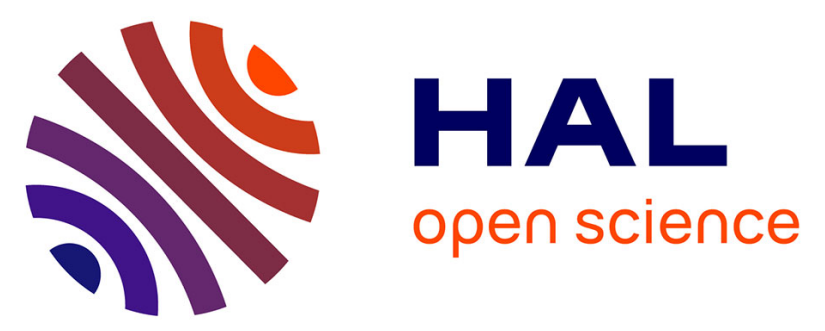

\title{
INSIDE Interactive and Non-destructive Solution for Introspection in Digital Environments
}

Flavien Lécuyer, Valérie Gouranton, Ronan Gaugne, Théophane Nicolas, Grégor Marchand, Bruno Arnaldi

\section{To cite this version:}

Flavien Lécuyer, Valérie Gouranton, Ronan Gaugne, Théophane Nicolas, Grégor Marchand, et al.. INSIDE Interactive and Non-destructive Solution for Introspection in Digital Environments. Digital Heritage 2018 - 3rd International Congress \& Expo, IEEE, Oct 2018, San Francisco, United States. pp.1-4. hal-01875793

\section{HAL Id: hal-01875793 https://hal.science/hal-01875793}

Submitted on 17 Sep 2018

HAL is a multi-disciplinary open access archive for the deposit and dissemination of scientific research documents, whether they are published or not. The documents may come from teaching and research institutions in France or abroad, or from public or private research centers.
L'archive ouverte pluridisciplinaire HAL, est destinée au dépôt et à la diffusion de documents scientifiques de niveau recherche, publiés ou non, émanant des établissements d'enseignement et de recherche français ou étrangers, des laboratoires publics ou privés. 


\section{INSIDE \\ Interactive and Non-destructive Solution for Introspection in Digital Environments}

\author{
Flavien Lécuyer \\ Univ Rennes, INSA Rennes, \\ Inria, CNRS, IRISA \\ Email: flavien.lecuyer@irisa.fr
}

\author{
Théophane Nicolas \\ Inrap, UMR 8215 Trajectoires \\ Email: theophane.nicolas@inrap.fr
}

\author{
Valérie Gouranton \\ Univ Rennes, INSA Rennes, \\ Inria, CNRS, IRISA \\ Email: valerie.gouranton@irisa.fr \\ Gregor Marchand \\ Univ Rennes, CNRS, CReAAH \\ Email: gregor.marchand@univ-rennes1.fr
}

\author{
Ronan Gaugne \\ Univ Rennes, Inria, CNRS, IRISA \\ Email: ronan.gaugne@irisa.fr
}

\author{
Bruno Arnaldi \\ Univ Rennes, INSA Rennes, \\ Inria, CNRS, IRISA \\ Email: bruno.arnaldi@irisa.fr
}

\begin{abstract}
The development of scanning technologies allowed to limit the destructiveness induced by the excavation. However, it is not enough, as the rendering is not enough to study a scanned artifact. We propose to use virtual reality as a legitimate tool for the inspection of artifacts modelled in 3D: INSIDE, with tools to lead a complete virtual excavation. This tool opens a new way of practicing archaeology, more efficient and safer for the content being excavated. A video presentation is also available at https://youtu.be/XaYvMvRO8-Y.
\end{abstract}

\section{INTRODUCTION}

In the early 90s, Reilly [1] was describing virtual archaeology, a possible future for archaeology using the latest technological advances to allow more discoveries with fewer risks. However, as he states in [2], progress in virtual archaeology since then has been timid, and virtual reality has mainly been a means of communication and visualization for archaeologists.

Our project, led by archaeologists (from Inrap and CNRS) and computer scientists (from Inria, Irisa, INSA, Univ Rennes), aims to create new tools, based on virtual reality, to improve the work process in archaeology. It includes the use of scanners to transform artifacts into 3D models. More than just storing those models, we want to unlock their potential, by using them as interactive material for archaeological study.

With this goal in mind, we created INSIDE, a virtual reality tool designed to let archaeologists easily interact with those 3D models, similarly to a physical study. This way, we intend to encourage the use of non-destructive methods in archaeology.

In Section II, we present the needs voiced by the archaeologists, used to evaluate existing solutions in Section III. We present our solution, INSIDE, in Section IV to VIII.

\section{COMPONENTS OF AN IDEAL FRAMEWORK}

For the exploitation of 3D model in an archaeological study context, a simple 3D viewer is not enough. By observing the work of the archaeologists, and through discussions between computer scientists and archaeologists, we identified some criteria for a good study of archaeological material:
- 3-dimensional view The material must be studied from all possible angles, rather than on a 2D representation.

- Full-scale display The display scale must be changed if needed, and a 1:1 scale should allow to get the volumes.

- Interaction with separate parts For composite models, each part should function independently, and the manipulation will highlight the links between the parts.

- Change of subject The model used in the application should be easy to change for an archaeologist.

\section{STATE OF THE ART}

\section{A. Teaching applications}

Some applications have been designed to teach the main principles of archaeology to students. The first of them, the SYASS [3], makes the students face the major constraints encountered in excavations. The same goal is targeted in $A$ Virtual Dig (Cooper) [7], with a toy example created for the application, and Virtual Dig (McPherron and Dibble) [5] ${ }^{1}$ with the site of Combe-Capelle (France).

Clonehenge [4] chooses another approach: it is mainly targeting the study of negative prints, with an example inspired from Arbor Low (Derbyshire). The Virtual Dig (Dunn) [6] is also worth noting, since it provides a simplified view of a site for a large public in the Israel Museum. The same idea is present in the game Excavate! [8], with a focus on the management of the excavation.

The major problem of those applications is that they do not provide the possibility of studying different sites, but instead come with a predefined example. Another inconvenient is that they do only display the sites in $2 \mathrm{D}$, since they are made for a use with a standard GUI interface.

\footnotetext{
${ }^{1}$ Please note that, since the names of the different applications cited here are very similar, the name of the authors is appended for more clarity
} 


\begin{tabular}{|c|c|c|c|}
\hline Application & Interface & Manipulation of separate parts & Change of model \\
\hline \multicolumn{4}{|c|}{ Teaching applications } \\
\hline SYASS [3] & $2 \mathrm{D}$ & Field level manipulation & Predefined sites \\
\hline Clonehenge [4] & $2 \mathrm{D}$ with point of view changes & Field level manipulation & No \\
\hline Virtual Dig (McPherron and Dibble) [5] & $2 \mathrm{D}$ & No & No \\
\hline The Virtual Dig (Dunn) [6] & $2 \mathrm{D}$ & Field level manipulation & No \\
\hline A Virtual Dig (Cooper) [7] & $2 \mathrm{D}$ & No & No \\
\hline Excavate! [8] & 2D & Field level manipulation & No \\
\hline \multicolumn{4}{|c|}{ Archaeological study applications } \\
\hline VITA [9] & Augmented reality (HMD) & Yes & Sites only \\
\hline GeoTUI [10] & Projective augmented reality & Yes & Sites only \\
\hline ArcheoTUI [11] & $2 \mathrm{D}$ with point of view changes & Yes & Yes \\
\hline Virtual manipulation of artifacts [12] & Stereoscopic screen & Object-wise & Objects or static sites only \\
\hline Submarine archaeology [13] & Virtual reality $\left(\mathrm{CAVE}^{\mathrm{TM}}\right)$ & Yes & Sites only \\
\hline
\end{tabular}

EVALUATION OF THE EXISTING VIRTUAL EXCAVATION APPLICATIONS (ORDERED BY DATE)

\section{B. Study applications}

Other applications targeted the study of scanned artifacts, thanks to a 3D visualization of the objects. The closer one to our tool can be found in Haydar's work [13], simulating the exploration of a submarine site. However, some assumptions are made, such as the large area covered by the sites, which can be problematic for the study of small artifacts. GeoTUI [10] allows to study the terrain with tangible props to find information about the relief, which can be interesting for the preparation of an excavation. However, what is inside the terrain is not studied. The system VITA [9] uses augmented reality to navigate in a site, with the Harris matrix as a menu, to get a view of a previously scanned site with the possibility of handling separate objects to study them further.

Forte and Kurillo's work [12] is more centered on the objects, and offer collaborative manipulation to share knowledge between the archaeologists. However, the application is designed to handle the object as a whole, so it is not possible to study, for instance, something covered with sediment.

ArcheoTUI [11] permits the user to gain efficiency in the reconstruction of fragmented artifacts, thanks to a system of semi-automatic matching helping the user. For some kinds of objects, with little to no degradation, a fully automatic reconstruction would be possible, as proposed in [14] for stone or in [15] for ceramics.

\section{PRoposed methodology}

First, it is to note that a virtual excavation serves as a support to the real one, as hinted in [16]. With a virtual excavation, we can study the disposition of the fragments inside an artifact, which already gives plenty of information concerning the process that generated the artifact, and on how to manage the future excavation. For some artifacts (e.g. with very little content), this real excavation may even be considered useless after the virtual one.

This implies to integrate a new set of tools in the archaeological process. What we propose is composed of three main steps, illustrated in Figure 1 for an $u^{2}{ }^{2}$ :

1) Scan of the subject First, when an artifact is to be studied in virtual reality, the first thing to do is to

\footnotetext{
${ }^{2}$ You can find more details on this object in [17]
}

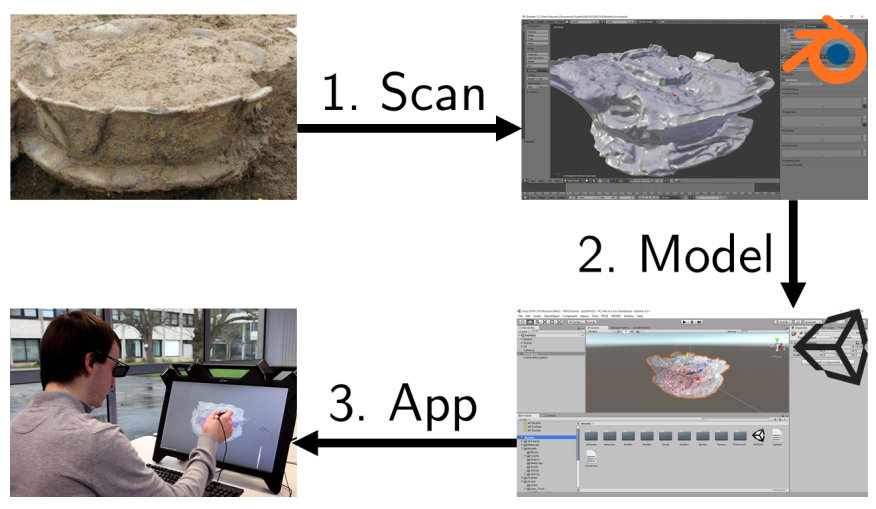

Fig. 1. Digital process for an archaeological study

scan it through tomodensitometry (also called CT scan), photogrammetry and TLS (Terrestrial Laser Scanning). For more information on their uses, please refer to [18] for TLS and photogrammetry and to [19] for CT scan. It is to note that we make virtually no difference between an object and a site in the process, as both can be studied in virtual reality.

2) Generation of the $3 D$ model From the data obtained through the scan, we create a 3D model. A computer scientist intervenes at this step if needed.

3) Study of the model in virtual reality The 3D model is integrated in the application, on any device. More information on the configuration is given in Section VII

In the application, the model is displayed with arbitrary colors, which eases the visualization of the artifacts. Although a photo-realistic rendering could have its advantages, it is important to note that it is not always the best modality, as stated in [20].For legibility reasons, the contouring of the outmost object (in our example, the urn) is displayed as a partly transparent object, which lets the user see the interior of the object directly.

\section{INTERACT WITH THE OBJECTS}

We integrate virtual reality in the archaeological process, with a tool on different devices. For smaller artifacts, a workbench (the zSpace, see Figure 2) is not too invasive, 


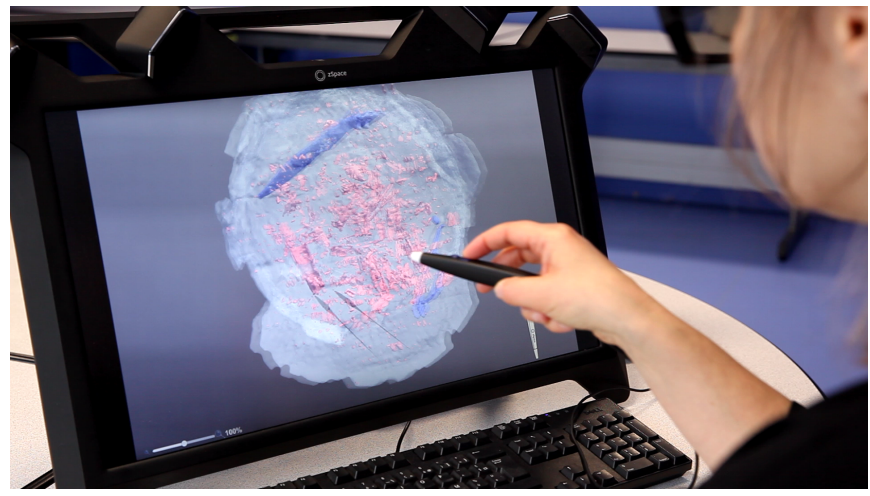

Fig. 2. The zSpace is a stereoscopic screen with a stylus for interaction

which is quite useful. For larger ones, a more immersive device is preferable, for instance a $\mathrm{CAVE}^{\mathrm{TM}}$ or a Head-Mounted Display.

In the 3D model, we have multiple parts. They can be moved independently. This allows the user to manipulate them freely, whereas this could be risky with the real fragments. A virtual reconstruction is easily done thanks to the $3 \mathrm{D}$.

Another advantage is the presence of very small fragments, which could be invisible during the real excavation, but can be seen here. For instance, spongy tissue is quite distinguish through the density, while the coloration may not suffice.

In a real excavation, once objects are out of the context, they cannot be placed again in it. In virtual reality, this is quite easy to do, with an undo/redo function, as well as a reset one.

In order to complete the virtual excavation, we also implement some tools, inspired by the tools an archaeologist would use in a real excavation.

\section{A. Ruler}

In order to let the user get correct measures in the application, we propose to use a ruler tool. This tools functions by using tag points, placed by the user. The user can create as many tag points as she wants; the measure is computed as the sum of distances between the pairs of tag points. To remind the user the order of the tag points, the measured segments are displayed on the screen. The main point of allowing more than two tag points is that it allows the users to measure non-linear surfaces in a natural way.

\section{B. Cutting plane}

Many artifacts are filled with very small fragments, making the direct study from the 3D model difficult, because heaps of small fragments deteriorate the visibility. To study the interior of artifacts or sites, the archaeologist usually gets a glimpse of its vertical organization by realizing a cutting plane. For this reason, we added a cutting plane, which can be moved dynamically, to hide a part of the studied object.

\section{Magnifying glass}

This tool allows the user to get more detail on the surface of an object, and still keep it in its current spatial context.
It is also possible to zoom on the entire object, as a global change of scale is sometimes more useful.

The minimum and maximum zoom values can be set. Of course, zooms are not only needed when using the magnifying glass: at any moment during the digital introspection, the user can feel the need to zoom. To allow this change of scale at any moment, a slider is displayed to change the scale.

\section{ANNOTATION SYSTEM}

- Object annotations In the 3D model, each separated object is considered as a possible find. As such, each one of them can be interesting for the archaeologist. Therefore, the archaeologist must be able to keep a track of the observations. The user can open an annotation text box to add information on the object. The annotations are free of any constraint for their format.

- Sticky notes Sometimes, the annotations on the objects are not enough. In fact, observations can also be done on any place of the artifact. A common system to add information at a given place in the real life is to place a sticky note. We decided to recreate the sticky notes in the virtual environment to make the interaction as natural as possible for the user. The text fields for the sticky notes are the same as those for the objects. After a note has been placed, the user can move it around if needed. The edition of a document is also available from the application to create a first version of a report. The document can then be edited from an outside editor.

\section{CONFIGURATION}

Creating an application can be tedious for an archaeologist. However, many tools now make the creation of a 3D model easy. We wanted to make the configuration of INSIDE as automatic as possible, through the Unity3D editor.

With a simple drag-and-drop of the object in the editor, the object is added to the application. The user can then just use a script, which will automatically make the model interactive, with the definition of a container and its contents.

\section{EVALUATION OF THE FRAMEWORK}

Three archaeologists with different specialties tried INSIDE to highlight the advantages and drawbacks of the method.

We used several artifacts for the study, including urns acquired with a CT scan. The model was then integrated in the application. The total process can be executed in a matter of a few hours (approx. five) for an object, with the archaeologist overseeing each step.

As expected, the virtual introspection was really useful to get more information, as the visualization inside the urns shows well the different dispositions of the content, with 3D fragments at the real scale. This is to be linked with our first two criteria (3-dimensional view and Full-scale display).

In addition, large fragments - more than $2-3 \mathrm{~cm}$ - were identifiable, allowing to classify the bones within the application. However, it cannot be done with certainty, since small relief cannot be provided here. The identification of the fragments 
was eased by the manipulation of each fragment on its own, to isolate them from the rest. This validates our interaction with separate parts criterion. Contrary to the direct visualization of the tomodensitometry, which requires some expertise to get the correct points of view, virtual reality provides a 3D interaction. For instance, manipulating a cutting plane is natural in $3 \mathrm{D}$.

Even though the information obtained was limited by what the scan could give (density and form), it prepares the real excavation, to concentrate the effort on the regions of interest. We plan to evaluate this further with an incoming excavation.

To summarize the main advantages of such an application:

- Important information can be obtained

- You can prepare the real excavation

- It's integrated in the archaeological process

- You save time for the excavation

\section{CONCLUSION}

We proposed a new methodology for the study of archaeological material, based on virtual reality. Thanks to a virtual study of the objects, new opportunities arise for the archaeologists, who can obtain much information before even starting the excavation. This methodology provides help in the decision process encompassing the excavation. For instance, the archaeologist can now decide not to excavate an object if its content is not worth the effort in the short term.

The archaeologists who tried our tool highlighted the new possibilities this offers for the study of hidden content, mostly for the preparation of the real excavation that could come afterward, but also the impact for formation when used after the excavation. For instance, it is to note that the urn presented in the document does no longer exist in its original form, since it has been excavated. This application serves also as a digital print of the existence of this urn. This new method for the study of archaeological material, with the use of virtual reality as both a preservation means and a complete study tool, could be the starting point for a new era of archaeology, as in [1].

\section{ACKNOWLEDGMENT}

The authors would like to thank Kévin Lamblot who initiated the application. This work is part of the ANR-16FRQC-0004 INTROSPECT project (http://introspect.info). We also thank the members of the INTROSPECT project, and particularly Isabelle Le Goff (anthropologist at Inrap) for her feedback.

\section{REFERENCES}

[1] P. Reilly, "Towards a virtual archaeology," in Computer Applications in Archaeology. Oxford: British Archaeological Reports, 1990, pp. 133-139. [Online]. Available: http://eprints.soton.ac.uk/id/eprint/353058

[2] G. Beale and P. Reilly, "After virtual archaeology: Rethinking archaeological approaches to the adoption of digital technology," Internet Archaeology, vol. 44, pp. -, 2017. [Online]. Available: http://intarch.ac.uk/journal/issue44/1/index.html

[3] B. O'Flaherty, “The southampton-york archaeological simulation system," Computer and Quantitative Methods in Archaeology 1988, vol. ii, pp. 491-498, 1988. [Online]. Available: http://proceedings. caaconference.org/files/1988/34_OFlaherty_CAA_1988-II.pdf
[4] M. Fletcher and D. Spicer, "Clonehenge: an experiment with gridded and non-gridded survey data," Computer and quantitative methods in archaeology, vol. 2, pp. 309-325, 1988. [Online]. Available: https: //bibliographie.uni-tuebingen.de/xmlui/bitstream/handle/10900/62260/ 20_Fletcher_Spicer_CAA_1988-II.pdf?sequence=2\&isAllowed=y

[5] S. P. McPherron and H. L. Dibble, "Virtual dig website," 2000 [Online]. Available: https://web.archive.org/web/20021127152856/http: //www.virtualdig.com:80/

[6] R. Dunn, "The virtual dig," in ACM SIGGRAPH 2002 Conference Abstracts and Applications, ser. SIGGRAPH '02. New York, NY, USA: ACM, 2002, pp. 122-123. [Online]. Available: http: //doi.acm.org/10.1145/1242073.1242139

[7] D. Cooper, "A virtual digjoining archaeology and fiction to promote critical and historical thinking," The Social Studies, vol. 94, no. 2, pp. 69-73, 2003. [Online]. Available: http://dx.doi.org/10.1080/ 00377990309600185

[8] scriptwelder, "Excavate!" 2015, game designed for the public presentation of Nowe Monasterzysko excavation. [Online]. Available: https://armorgames.com/play/17843/excavate

[9] H. Benko, E. W. Ishak, and S. Feiner, "Collaborative mixed reality visualization of an archaeological excavation," in Proceedings of the 3rd IEEE/ACM International Symposium on Mixed and Augmented Reality, ser. ISMAR '04. Washington, DC, USA: IEEE Computer Society, 2004, pp. 132-140. [Online]. Available: http://dx.doi.org/10.1109/ISMAR.2004.23

[10] N. Couture, G. Rivière, and P. Reuter, "Geotui: A tangible user interface for geoscience," in Proceedings of the $2 \mathrm{Nd}$ International Conference on Tangible and Embedded Interaction, ser. TEI '08. New York, NY, USA: ACM, 2008, pp. 89-96. [Online]. Available: http://doi.acm.org/10.1145/1347390.1347411

[11] P. Reuter, G. Riviere, N. Couture, S. Mahut, and L. Espinasse, "Archeotui\&driving virtual reassemblies with tangible $3 \mathrm{~d}$ interaction," J. Comput. Cult. Herit., vol. 3, no. 2, pp. 4:1-4:13, Oct. 2010. [Online]. Available: http://doi.acm.org/10.1145/1841317.1841319

[12] M. Forte and G. Kurillo, "Cyberarchaeology: Experimenting with teleimmersive archaeology," in 2010 16th International Conference on Virtual Systems and Multimedia, Oct 2010, pp. 155-162. [Online]. Available: http://dx.doi.org/10.1109/VSMM.2010.5665989

[13] M. Haydar, "Interaction en réalité mixte appliquée l'archéologie sous-marine," Ph.D. dissertation, Université d'Évry, 2011, thse de doctorat dirige par Mallem, Malik Informatique Evry-Val d'Essonne 2011. [Online]. Available: http://www.theses.fr/2011EVRY0028

[14] Q.-X. Huang, S. Flöry, N. Gelfand, M. Hofer, and H. Pottmann, "Reassembling fractured objects by geometric matching," in ACM SIGGRAPH 2006 Papers, ser. SIGGRAPH '06. New York, NY, USA: ACM, 2006, pp. 569-578. [Online]. Available: http://doi.acm.org/10. $1145 / 1179352.1141925$

[15] M. Kampel and R. Sablatnig, "Virtual reconstruction of broken and unbroken pottery," in Fourth International Conference on 3-D Digital Imaging and Modeling, 2003. 3DIM 2003. Proceedings., Oct 2003 , pp. 318-325. [Online]. Available: http://dx.doi.org/10.1109/IM.2003. 1240265

[16] H. D. Huisman, D. Ngan-Tillard, M. A. Tensen, F. J. Laarman, and D. C. Raemaekers, "A question of scales: studying neolithic subsistence using micro ct scanning of midden deposits," Journal of Archaeological Science, vol. 49, no. Supplement C, pp. 585 - 594, 2014. [Online]. Available: http://www.sciencedirect.com/science/article/ pii/S0305440314001794

[17] T. Nicolas, R. Gaugne, C. Tavernier, Q. Petit, V. Gouranton, and B. Arnaldi, "Touching and interacting with inaccessible cultural heritage," Presence: Teleoperators and Virtual Environments, vol. 24, no. 3, pp. 265-277, 2015. [Online]. Available: http://dx.doi.org/10. 1162/PRES_a_00233

[18] M. Wilkinson, R. Jones, C. Woods, S. Gilment, K. McCaffrey, S. Kokkalas, and J. Long, "A comparison of terrestrial laser scanning and structure-from-motion photogrammetry as methods for digital outcrop acquisition," Geosphere, vol. 12, no. 6, p. 1865, 2016. [Online]. Available: http://dx.doi.org/10.1130/GES01342.1

[19] P. K. Lewin and D. C. Harwood-Nash, X-ray computed axial tomography of an ancient Egyptian brain. MTP, International Research Communications, 1977.

[20] L. Pujol-Tost, "Archaeology, museums and virtual reality," Digit-HVM, vol. 3, pp. 1-9, 5 2004. [Online]. Available: http://www.uoc.edu/humfil/ articles/cat/pujol0304/pujol0304.pdf 